\title{
Unlicensed and off label prescribing of drugs in general practice
}

\author{
J McIntyre, S Conroy, A Avery, H Corns, I Choonara
}

\begin{abstract}
Aim-To determine the incidence and nature of unlicensed and off label prescribing of drugs for children in general practice.

Methods-A retrospective analysis of all prescriptions for one year involving children (aged 12 years or under) from a single suburban general practice in the English Midlands. Prescribed drugs were categorised as licensed, unlicensed (without a product licence), or used in an off label way (outside the terms of their product licence).

Results-During 1997 there were 3347 prescription items involving 1175 children and 160 different drugs. A total of 2828 $(84.5 \%)$ prescriptions were for licensed medicines used in a licensed way; 10 $(0.3 \%)$ were for unlicensed medicines; and $351(10.5 \%)$ were licensed medicines used in an off label way. For $158(4.7 \%)$ the information was insufficient to determine licence status.

Conclusion-This is the first study to show that a significant number of drugs prescribed for children by general practitioners are off label and highlights the anomalies and inadequacies of drug information for prescribers.

(Arch Dis Child 2000;83:498-501)
\end{abstract}

Keywords: unlicensed prescribing; off label prescribing; drugs; general practice

Academic Division of Child Health (University of

Nottingham),

Derbyshire Children's

Hospital, Uttoxeter

Road, Derby

DE22 3NE, UK

J McIntyre

S Conroy

H Corns

I Choonara

Division of General Practice, School of Community Health Sciences, University

Hospital, Nottingham NG7 2UH, UK

A Avery

Correspondence to:

Dr McIntyre

John.Mcintyre@,

nottingham.ac.uk

Accepted 13 July 2000

The drug licensing regulatory process was introduced by the Medicines Act of 1968. It was set up to ensure that drugs sold or supplied in the UK are safe, effective, and of high quality.

Recent hospital based studies show that many drugs used in children are either not licensed (unlicensed) or are prescribed outside the terms of the product licence (off label). ${ }^{1-4}$ On general paediatric surgical and medical wards, $36 \%$ of children receive at least one drug that is either unlicensed or off label during their inpatient stay. ${ }^{2}$ In paediatric intensive care this figure is $70 \%^{3}$ and in neonatal intensive care $90 \% .{ }^{1}$ A recent study of children's wards in five European countries found almost half of all prescriptions were either unlicensed or off label. ${ }^{5}$ This suggests that many children in hospital are exposed to drugs without the guarantees the regulatory process should ensure. There is now evidence that the incidence of adverse drug reactions in hospitalised children is higher for unlicensed or off label drugs than licensed preparations. ${ }^{6}$
Hospital inpatients represent a relatively small number compared with those accessing health care via general practitioners (GPs). There is clearly the potential for many children to receive drugs in the community that are unlicensed or off label and be exposed to the inherent risks this may carry. However, the incidence of unlicensed and off label prescribing by general practitioners is unknown.

The aim of this study was to establish the incidence and nature of unlicensed and off label prescribing of drugs for children in a general practice setting.

\section{Methods}

Prescription records for every child of 12 years of age or under, receiving a prescription in the year of 1997 were provided from the computer prescribing system of a single suburban general practice in the English Midlands. The practice records full details of almost all acute and repeat prescriptions on its computer system (Genisyst).

The practice had a list size of 9234 patients, of whom 865 were children less than 5 years ( 437 boys, 428 girls) and 1807 were 12 years or under (913 boys, 894 girls). Children aged 12 years or under therefore represent $20 \%$ of the total number of patients in the practice. New housing estates and an Army Depot in the catchment area explain the high proportion of children on the list. The Jarman score for the practice is -3.48 , suggesting a population close to average in terms of deprivation.

Information from the computerised records

of prescriptions included the patient's date of birth, sex, the issue date of the prescription, drug, formulation, quantity, and directions for use. This information was entered onto an SPSS statistical software package.

The prescription records were analysed by the research pharmacist (SC) and student (HC). Drugs were classified according to the Anatomical Therapeutic Chemical Classification (ATC). ${ }^{7}$ Information on the product licence was derived from the Compendium of data sheets and summaries of product characteristics $1998-99,{ }^{8}$ the British national formulary, ${ }^{9}$ the medical information department at the pharmaceutical company concerned, or the package insert. This information was then used to determine whether drugs prescribed were licensed, unlicensed (without a product licence), or used in an off label manner (outside the terms of their product licence). The prescriptions were then categorised into one of the following six groups (see table 1 for examples): 
Table 1 The licence status

\begin{tabular}{|c|c|c|}
\hline Licence status & $\begin{array}{l}\text { Number of } \\
\text { prescriptions (\%) } \\
(n=3347)\end{array}$ & Example \\
\hline Licensed & $2828(84.5)$ & \\
\hline \multicolumn{3}{|l|}{ Unlicensed } \\
\hline $\begin{array}{l}\text { Modified by community } \\
\text { pharmacist }\end{array}$ & $8(0.2)$ & Dilution of steroid cream \\
\hline “Special formulation" & $2(0.1)$ & White soft paraffin/liquid paraffin 50:50 \\
\hline Total unlicensed & $10(0.3)$ & \\
\hline \multicolumn{3}{|l|}{ Off label } \\
\hline Age & $28(0.8)$ & Co-amoxiclav $375 \mathrm{mg}$ tablets in 11 year old \\
\hline Dose & $320(9.6)$ & $\begin{array}{l}\text { Sodium cromoglycate inhaler prescribed twice } \\
\text { daily }\end{array}$ \\
\hline Route & $3(0.1)$ & Salbutamol inhaler through half volumatic \\
\hline Total off label & $351(10.5)$ & \\
\hline Incomplete data & $158(4.7 \%)$ & \\
\hline
\end{tabular}

Table 2 The ten most frequently prescribed drugs

\begin{tabular}{lll}
\hline Drug & $\begin{array}{l}\text { Number (\%) of } \\
\text { prescription items } \\
(n=3347)\end{array}$ & $\begin{array}{l}\text { Number (\%) } \\
\text { unlicensed or off } \\
\text { label }\end{array}$ \\
\hline Paracetamol & $299(8.9)$ & $16(5.4)$ \\
Amoxicillin & $288(8.6)$ & $32(11.1)$ \\
Salbutamol & $276(8.2)$ & $10(3.6)$ \\
Beclometasone & $183(5.5)$ & $21(11.5)$ \\
Hydrocortisone & $140(4.2)$ & $0(0.0)$ \\
Aqueous cream & $133(4)$ & $1(0.8)$ \\
$\begin{array}{l}\text { Penicillin } \\
\text { Oilatum }\end{array}$ & $120(3.6)$ & $27(22.5)$ \\
Chloramphenicol & $115(3.4)$ & $0(0.0)$ \\
Malathion & $113(3.4)$ & $7(6.2)$ \\
Total & $108(3.2)$ & $2(1.9)$ \\
\hline
\end{tabular}

(1) Licensed drug used in licensed way

(2) Unlicensed medicines as a result of modification of a licensed drug by a community pharmacist

(3) Unlicensed medicines as a result of "special" formulation of a licensed drug by a pharmaceutical company under a manufacturing licence

(4) Off label use of medicine with respect to age

(5) Off label use of medicine with respect to dose

(6) Off label use of medicine with respect to route of administration.

It was not possible to determine whether drugs prescribed were used for licensed indications. Therefore the incidence of off label use may actually be greater than that established in this study.
When there was insufficient information to determine the licence status, the prescription was identified as being incomplete.

\section{Results}

Over the one year study period, 1175 children received at least one prescription; this was $65 \%$ of all children aged 12 years or under on the practice list. There were 3347 prescription items in total, involving 160 different drugs. The median number of prescription items per child was two (range 1-21). Of the 3347 prescription items, 2828 (84.5\%) were licensed medicines prescribed in a licensed way; 10 $(0.3 \%)$ were unlicensed medicines; and 351 $(10.5 \%)$ were licensed medicines prescribed in an off label way. For $158(4.7 \%)$ prescription items there was insufficient information to determine the licence status (see table 1).

Off label use of medicines with respect to dose was the largest category of unlicensed or off label prescriptions (see table 1). Of 361 unlicensed or off label prescription items, 320 $(89 \%)$ were off label with respect to dose, representing $9.6 \%$ of the total prescription items.

Table 2 shows the ten most commonly prescribed drugs; these account for over half of all prescription items. Table 3 shows the ATC classification of drugs, the number of unlicensed and off label items, and the number of off label items with respect to dose. Systemic antibacterial agents comprised the largest group of drugs prescribed, followed by antiasthmatics and emollients/protectives. Together these three groups accounted for half of all prescriptions and half of unlicensed/off label prescribing.

Of 677 prescriptions for systemic antibacterial drugs, $106(16 \%)$ were prescribed in an unlicensed/off label manner and 101 of these were off label for dose (see table 3). In 88 of these prescriptions doses were lower than recommended and in 10 higher than recommended. The remaining three were at nonrecommended dosing intervals. The majority of antiasthmatics involved in off label prescribing were higher than licensed doses of inhaled steroid preparations and lower than licensed doses of inhaled sodium cromoglycate.

Table 3 Prescription analysis according to drug group

\begin{tabular}{|c|c|c|c|c|}
\hline Drug group & ATC classification & $\begin{array}{l}\text { Total number of } \\
\text { prescriptions }(\%) \\
(n=3347)\end{array}$ & $\begin{array}{l}\text { Number of unlicensed } \\
\text { and off label } \\
\text { prescription items }\end{array}$ & $\begin{array}{l}\text { Number of prescription } \\
\text { items off label with } \\
\text { respect to dose }\end{array}$ \\
\hline Systemic antibacterials & J01 & $677(20)$ & $106(16)$ & $101(15)$ \\
\hline Antiasthmatics & R03 & $541(16)$ & $61(11)$ & $49(9)$ \\
\hline Emollients and protectives & D02 & $434(13)$ & $23(5)$ & $20(5)$ \\
\hline Analgesics & N02 & $313(9.5)$ & $16(5)$ & $16(5)$ \\
\hline $\begin{array}{l}\text { Ophthalmological and otological } \\
\text { preparations }\end{array}$ & S03 & $276(8)$ & $39(14)$ & $35(13)$ \\
\hline Dermatological corticosteroids & D07 & $177(5.5)$ & $2(1)$ & $0(0)$ \\
\hline Ectoparasiticides & P03 & $147(4.5)$ & $3(2)$ & $3(2)$ \\
\hline Dermatological antibiotics & D06 & $126(4)$ & $8(6)$ & $6(5)$ \\
\hline Systemic antihistamines & R06 & $111(3)$ & $37(33)$ & $30(27)$ \\
\hline Dermatological antifungals & D01 & $101(3)$ & $6(6)$ & $6(6)$ \\
\hline Laxatives & A06 & $51(1.5)$ & $13(25)$ & $13(25)$ \\
\hline $\begin{array}{l}\text { Antidiarrhoeal/anti-inflammatory/ } \\
\text { anti-infectives }\end{array}$ & $\mathrm{A} 07$ & $51(1.5)$ & $4(8)$ & $3(6)$ \\
\hline Anti-inflammatory/anti-rheumatics & M01 & $51(1.5)$ & $6(12)$ & $5(10)$ \\
\hline Other dermatologicals & D11 & $32(1)$ & 0 & $0(0)$ \\
\hline Others & & $259(8)$ & $37(14)$ & $33(13)$ \\
\hline Total & & $3347(100)$ & 361 & 320 \\
\hline
\end{tabular}

^Percentage total for each group in parentheses. 
We did not find a significant difference in the incidence of unlicensed/off label prescribing between age groups. With respect to age the greatest number of prescriptions occurred in the first year of life. There were 491 prescription items (15\% of total prescriptions) for children under 1 year: 76 were unlicensed/off label and 65 of these were off label for dose. Of unlicensed/off label prescriptions, systemic antibacterial drugs accounted for 34\%. Emollients and protectives at lower than licensed doses and antiasthmatics at larger than licensed doses were the other main groups.

\section{Discussion}

Many drugs pass through the licensing process without being evaluated in children. The product licence often contains statements such as "not recommended for use in children", or "no evidence for use in children". This usually reflects an absence of data in children rather than a specific reason for the drug not to be used. Children in hospital commonly receive unlicensed or off label drugs..$^{1-5}$ This suggests that out of necessity medicines are prescribed for children without the safety, efficacy, and quality assurance the licensing process should ensure. This study is the first to show that a similar problem exists for prescriptions in general practice.

This study was based on a single practice. This has allowed us to examine in detail a large volume of prescription information generated from a group of GPs. However, there are possible limitations. Firstly, some prescriptions may not have been recorded on the computer (for example, from home visits). Our pilot work suggests this would be a relatively small total number: we estimate over $95 \%$ of prescriptions would have been covered in the study. A second limitation is that we cannot be certain our observations would apply with a different group of GPs or in different settings, for example, a rural practice as opposed to this urban practice. Nevertheless, the setting is a practice close to average in terms of deprivation and the groups of drugs prescribed similar to those found in another primary care based study of prescriptions for children. ${ }^{10}$ The drugs making up the majority of unlicensed/off label prescriptions are likely to reflect common practice.

In this study very few prescription items were for unlicensed drugs $(0.3 \%)$. However, a considerable number were off label $(10.5 \%)$. Although this is a smaller proportion than reported from hospital settings it is important because of the large volume of prescriptions made for children by GPs. Over the one year study period 1175 children received at least one prescription; this is $65 \%$ of all children aged 12 years or under. Other studies have similarly found widespread prescribing for children. ${ }^{10}{ }^{11}$ In fact our study of prescriptions is likely to underestimate the amount of drugs used in the community. An unknown number of children will also be taking non-prescription medicines bought "over the counter" and the extent to which these are used outside the terms of the product licence has yet to be studied. Given the large volume of prescribing for children and widespread use of drugs in the community, it is essential that the regulatory framework ensures medicines in children are safe, effective, and of high quality.

Why should a significant proportion of prescriptions be off label? Does this represent poor prescribing practice or does it reflect the inadequacies of the product licence information? There is no suggestion in this study that hazardous prescriptions were being made and it was not the aim of the study to determine if the prescriptions were necessary. In a study that did look at the quality of prescribing for children in general practice, 6331 scripts were reviewed and only about $1 \%$ could legitimately be called into question. ${ }^{12}$

Our data show that prescriptions outside of the product licence occur in the groups of drugs most commonly prescribed. We suggest this reflects inadequacies of the product licence information with respect to children.

Systemic antibacterial drugs were the largest group of drugs prescribed. They accounted for $29 \%$ of the unlicensed/off label prescription items (see table 3). Of 101 prescription items off label for dose, 88 of these were doses lower than recommended. We speculate that the reason for so many apparently low dose prescriptions is the age range groupings in the product licence. The following are examples. Amoxicillin and ampicillin have one licensed dose recommendation for children up to 10 years, and thereafter they are recommended to receive adult doses. ${ }^{8}$ There is an enormous weight range in children from birth up to 10 years of age. Common practice is to adjust the dose according to size, so making many of the prescriptions fall outside the product licence recommendations. Flucloxacillin, erythromycin, and penicillin $\mathrm{V}$ all have different age ranges for dose recommendations. There does not appear to be any sound reasoning for these somewhat arbitrary and confusing age groupings. That a newborn baby and a 10 year old child should receive similar doses of amoxicillin does not seem sensible. GPs who are anxious to make safe and effective prescriptions for children cannot rely on product information.

Standardising to age groups based on physiological and developmental reasoning may help to minimise the current confusion. The 1996 joint report of the then British Paediatric Association and the Association of the British Pharmaceutical Industry made such recommendations. ${ }^{13}$ The suggested age ranges were birth to 1 month, 1 month to 2 years, 2-12 years, and 12-18 years based on significant physiological and developmental milestones in a child's life. Adoption of these recommendations for both new and old drugs by the pharmaceutical industry and regulatory authorities would simplify and improve prescribing. The antibiotic examples shown above illustrate a problem common across drug groups used in children.

For antiasthmatics involved in off label prescribing the majority were higher than licensed doses of inhaled steroid preparations and lower than licensed doses of inhaled 
sodium cromoglycate. The off label prescribing of inhaled steroids probably reflects licensed doses not being in accordance with the current British Thoracic Society guidelines for the treatment of chronic asthma in schoolchildren. ${ }^{14}$ If there is sufficient information to back up the guidelines it should be enough to satisfy the licensing requirements. The current licensing process is not able to keep up to date with current practice and there is no system to monitor and coordinate this information and make it available for such a use.

There are clearly shortfalls in the current licensing framework in providing comprehensive information for use of drugs in children. The regulatory authorities are limited by the constraints of the Medicines Act. They are dependent on initiatives by the pharmaceutical industry. However, paediatric studies may be perceived as difficult and expensive. There are no incentives for the pharmaceutical industry to carry out such studies, particularly as their products already have widespread use. The current situation regarding the use of medicines in children has been recognised as unacceptable by paediatricians, the pharmaceutical industry, politicians, and implicitly by the regulatory authority. ${ }^{13} 15$

Medicines for children, published by the Royal College of Paediatrics and Child Health ${ }^{16}$ is a welcome attempt to improve information for prescribers on drugs used in children. However, for medicines to be safe and effective information from clinical studies is required. To address the ethical and practical difficulties of carrying out such clinical trials and to provide the required comprehensive information requires scientific studies by experienced teams. The Department of Health and the pharmaceutical industry support the need for such studies but to date have been reluctant to fund them. In the USA the government funded an extensive Paediatric Pharmacology Research Unit Network with 13 centres. A European Network for Drug Investigation in Children has been established by interested professionals. ${ }^{17} 18$ Unfortunately funding for research into the use of medicines in children is not considered a priority, either in Europe or the UK.
CONCLUSION

In conclusion, we found that an appreciable number of GP prescriptions for children are drugs used in an off label way. The reason for this is not hazardous prescribing practices but rather anomalies and inadequacies of product licence information with respect to children. Children deserve the safety, efficacy, and quality of medicines that the regulatory process affords to adults and such anomalies and inadequacies need to be addressed.

We thank the GP practice for allowing this study to be conducted and to Mr J Parker for extracting data from the computer system.

1 Conroy S, McIntyre J, Choonara I. Unlicensed and off label drug use in the neonate. Arch Dis Child Fetal Neonatal Ed 1999;80:F142-4.

2 Turner S, Longworth A, Nunn AJ, Choonara I. Unlicensed and off label drug use in paediatric wards: prospective study. BMF 1998;316:343-5.

3 Turner S, Gill A, Nunn T, Hewitt B, Choonara I. Use of "off-label" and unlicensed drugs in paediatric intensive care unit [letter]. Lancet 1996;347:549-50.

4 Turner S, Nunn A, Choonara I. Unlicensed drug use in children in the UK. Paediatric and Perinatal Drug Therapy 1997;1:52-5.

5 Conroy S, Choonara I, Impicciatore P, et al. Survey of unlicensed and off-label drug use in paediatric wards in European countries. BMF 2000;320:79-82.

6 Turner S, Nunn AJ, Fielding K, Choonara I. Adverse reactions to unlicensed and off-label drugs on paediatric wards. Acta Paediatr 1999;88:965-8.

7 WHO. Anatomical therapeutic chemical index with defined daily doses (DDDs). Geneva: WHO Collaborating Centre for Drug Statistics Methodology, 1997.

8 Association of the British Pharmaceutical Industry. Compendium of data sheets and summaries of product characteristics. London: Datapharm Publications, 1998-99.

9 BMA, RPSGB. British national formulary, vol. 35. London: BMA, RPSGB, 1998.

10 Straand J, Rokstad K, Heggedal U. Drug prescribing for hildren in general practice. A report from More \& Romsdal Prescription Study. Acta Paediatr 1998;87:218-24.

11 Rylance G, Woods C, Cullen R, Rylance M. Use of drugs by children. BMF 1988;297:445-7.

12 Catford J. Quality of prescribing for children in general practice. BMY 1980:280:1435-7.

13 BPA and ABPI. Licensing medicines for children. Joint report of the British Paediatric Association and the Association of the British Pharmacutical Industry. London: BPA, ABPI, 1996.

14 Anon. The British guidelines on asthma management; 1995 review and position statement. Thorax 1997;52 (suppl 1): $\mathrm{S} 1-\mathrm{S} 21$.

15 Health Committee. The specific health needs of children and young people. London: House of Commons, 1997.

16 Royal College of Paediatrics and Child Health and Neonatal and Paediatric Pharmacists Group. Medicines for

17 Bonati M, Choonara I, Hoppu K, Pons G, Seyberth H. Closing the gap in drug therapy. Lancet 1999;353:1625.

18 van den Anker J, Choonara I. ENDIC-European Network for Drug Investigation in Children. Paediatric and Perinatal Drug Therapy 1999;3:15-16. 